\title{
Evaluasi Implementasi Reamicroteaching di FISE dengan Sekolah Mitra.
}

Oleh : Suhadi Purwantara, Muhyadi, Abdul Ghofur

\begin{abstract}
Abstrak
Adanya keluhan dari beberapa tenaga kependidikan dan dosen terkait penambahan beban kerja di waktu libur dan pihak sekolah yang harus mengubah program pendidikan di sekolahnya untuk menyesuaikan program ini. Disamping itu beberapa guru yang terlibat dalam pelaksanaan realmicroteaching menyatakan kesulitan harus mengatur waktu jam mengajar dan mengulang setidaknya satu pertemuan. Berdasarkan beberapa permasalahan tersebut, peneliti merasa tertarik melakukan kajian terhadap implementasi Realmicroteaching di FISE UNY dengan judul "Evaluasi Implementasi Realmicroteaching FISE UNY dengan Sekolah Mitra"

Dalam penelitian ini populasi mencakup seluruh guru SMP, SMA, dan SMK di bebrapa sekolah mitra, dosen FISE UNY, mahasiswa, dan staff pendidikan FISE UNY. Selanjutnya teknik pengambilan sampel dilakukan secara acak yang telaah dikelompokkan (classified random sampling). Data dalam penelitian diklasifikasikan menjadi dua kelompok yaitu data primer dan data sekunder. Data primer diperoleh dari para dosen, guru, mahasiswa, dan karyawan dengan cara menyebarkan angket untuk diberikan respon. Data sekunder diperoleh dari kajian dokumen.

Hasil penelitian menunjukkan bahwa keterampilan mahasiswa pada saat PPL sekitar (63\%) menyatakan mahasiswa PPL mengalami peningkatan keterampilan. Sebanyak 22,2\% tidak memberikan pilihan jawaban dan sisanya $14,8 \%$ menyatakan tidak mengalami peningkatan. Biaya penyelenggaraan realmicroteaching dari fakultas relative besar sehingga membebani anggaran pengembangan tri dharma perguruan tinggi. Guru menyatakan bahwa sebagian besar $(81,4 \%)$ siap membantu pelaksanaan realmicroteaching dan sebagian besar $(68,1 \%)$ merasa senang melaksanakan realmicroteaching. Sekitar $(31,9 \%)$ saja yang menyatakan bahwa tidak senang melaksanakan realmicroteaching. Sikap dosen dengan pelaksaanaan realmicroteaching sebagian besar $(56,2 \%)$ menyatakan tidak senang (keberatan) dengan pelaksanaan realmicroteaching. Sikap siswa dengan pelaksaanaan realmicroteaching sebagian besar $(83,7 \%)$ menyatakan senang dengan pelaksanaan realmicroteaching
\end{abstract}

Keywords: realmicroteaching, sekolah mitra

\section{Pendahuluan}

Di Indonesia, pendidikan cenderung terfokus pada penguasaan aspek kognitif, pembelajaran berputar-putar pada pemahaman konsep, sehingga siswa tidak bersentuhan dengan dunia nyata atau lingkungan sekitar. Seringkali dapat diperhatikan di sekolah-sekolah guru fasih berbicara tentang konsep tetapi tidak mengaitkan dengan kehidupan seharihari, maupun fenomena yang terjadi di lingkungan sekitar. Guru kurang menyadari bahwa pemahaman konsep yang di ajarkan memerlukan contohcontoh dengan fenomena-fenomena yang sudah difahami dengan baik oleh 
siswa. Guru kurang mengembangkan potensi yang ada pada setiap siswa secara optimal. Untuk itu perlunya perguruan tinggi kependidikan mempersiapkan dengan baik calon lulusannya agar meluluskan calon guru yang benar-benar memiliki kompetensi pedagogic, kompetensi kepribadian, kompetensi social dan kompetensi profesional.

Kurikulum Program S1 Kependidikan FISE UNY mencantumkan empat kompetensi tersebut, serta menerapkan lima pilar yang ditetapkan DIKTI. Kelima pilar tersebut adalah kelompok Mata Kuliah Pengembangan Kepribadian (MPK), Mata Kuliah Keilmuan dan Keterampilan (MKK), Mata Kuliah Keahlian Berkarya (MKB), Mata Kuliah Perilaku Berkarya (MPB), Mata Kuliah Berkehidupan Bermasyarakat (MBB). Salah satu Mata Kuliah Keahlian Berkarya adalah Praktik Pengalaman Lapangan (PPL). PPL menjadi tolok ukur keberhasilan pendidikan untuk calon guru. PPL terdiri atas PPL I dengan cara peerteaching di kampus, dan PPL II berupa praktik mengajar di sekolah.

Selama enam tahun terakhir sejak tahun 2006 pelaksanaan PPL-I di FISE UNY ditambahkan dengan program realmicroteaching yaitu dengan mendatangkan para siswa dan guru dari beberapa sekolah mitra diajar langsung oleh mahasiswa yang akan ikut PPL II. Mahasiswa diberikan kesempatan selama 15 menit mengajar siswa tersebut, hampir sama dengan program PPL-I. Adanya program ini diharapkan mahasiswa dapat lebih siap mengajar terutama pada saat PPL II.

Di sisi lain, penyelenggaraan program ini berkonsekuensi terhadap anggaran tambahan yang dikeluarkan oleh fakultas sebagai penyelenggara. Fakultas harus mengeluarkan biaya akomodasi, transportasi, dan konsumsi bagi siswa yang didatangkan, guru, dan juga dosen, serta tenaga kependidikan yang terlibat yang jumlahnya mencapai puluhan hingga ratusan orang dalam sekali penyelenggaraan. Adanya keluhan dari beberapa tenaga kependidikan dan dosen terkait penambahan beban kerja di waktu libur dan pihak sekolah yang harus mengubah program pendidikan di sekolahnya untuk menyesuaikan program ini. Disamping itu beberapa guru yang terlibat dalam pelaksanaan realmicroteaching menyatakan kesulitan harus mengatur waktu jam mengajar dan mengulang setidaknya satu pertemuan.

Permasalahan-permasalahan dalam Realmicroteaching antara lain pertaanyaan tentang apakah realmicroteaching meningkatkan keterampilan mahasiswa pada saat PPL, biaya penyelenggaraan realmicroteaching dari fakultas, pendapat dosen dan staf pendidikan terkait optimalisasi pekerjaan dengan diselenggarakannya realmicroteaching, sikap sekolah dengan pelaksaanaan realmicroteaching, sikap siswa dengan pelaksaanaan realmicroteaching.

Berdasarkan perumusan masalah yang diuat, maka penelitian ini bertujuan:

1. Mengetahui peningkatan keterampilan mahasiswa pada saat PPL setelah mengikuti realmicroteaching.

2. Mengetahui besar biaya yang dikeluarkan oleh fakultas untuk pelaksanaan realmicroteaching. 
3. Mengetahui pendapat dosen dan staf pendidikan terkait optimalisasi pekerjaan dengan diselenggarakannya realmicroteaching.

4. Mengatahui sikap sekolah dengan pelaksaanaan realmicroteaching

5. Mengetahui sikap siswa dengan pelaksaanaan realmicroteaching.

\section{Kajian Teori}

Menurut Peraturan Pemerintah Nomor 19 tahun 2005 tentang Standar Nasional Pendidikan khususnya Bab VI Pasal 28 ayat 1 yang berbunyi: " pendidik harus memiliki kualifikasi akademik dan kompetensi sebagai agen pembelajaran, sehat jasmani dan rohani, serta memliki kemampuan untuk mewujudkan tujuan pendidikan nasional".

Menurut Zamroni (2001) pendidikan merupakan suatu rekayasa untuk mengendalikan pembelajaran guna mencapai tujuan yang direncanakan secara efektif dan efisien. Dalam proses rekayasa ini peranan pengajaran (teaching) sangat penting karena merupakan kegiatan yang dilakukan oleh guru untuk mentransfer pengetahuan, keterampilan dan nilai kepada siswa, sehingga apa yang ditransfer memiliki makna bagi diri sendiri, dan berguna tidak saja bagi diringa tetapi juga bagi masyarakatnya. Mengajar hanya dapat dilakukan dengan baik dan benar oleh seseorang yang memilki kualifikasi tertentu. Dengan kata lain mengajar adalah suatu profesi. Suatu pekerjaan dapat dikatakan sebagai suatu profesi apabila pekerjaan tersebut dapat didetailkan dalam perilaku dan langkah-langkah yang jelas dan relatif pasti. Kualifikasi tersebut antara lain telah memilki menempuh jenjang pendidikan tertentu dan memiliki kompetensi tertentu pula.

Penyelenggaraan kegiatan KKN-PPL mengacu pada UndangUndang Guru dan Dosen Nomor 14 tahun 2005, khususnya yang berkenaan dengan empat kompetensi guru, yakni: kompetensi pedagogik, kompetensi kepribadian, kompetensi sosial dan kompetensi profesional.

a. Kompetensi profesional

Kompetensi profesional seorang guru adalah seperangakat kemampuan yang harus dimiliki oleh seorang guru agar ia dapat melaksanakan tugas mengajarnya dengan berhasil (Hamzah B. Uno, 2007). Menurut Tim PPL UNY (2009) kompetensi profesional ditunjukan oleh berbagai kompetensi dasar yakni menguasai substansi mata pelajaran, memahami rantai kognitif, menguasai struktur dan materi kurikulum mata pelajaran yang berlaku; mengaitkan dan mengaplikasikan materi mata pelajaran sesuai dengan konteks dan lingkungan dalam kehidupan sehari-hari; serta mampu menyesuaikan materi pelajaran dengan perkembangan peserta didik.

b. Kompetensi Pedagogik

Kompetensi pedagogik mencakup sejumlah kompetensi dasar yakni: (1) menguasai model, strategi, pendekatan, metode dan media pembelajran; (2) merencanakan pembelajaran yang mendidik; (3) melaksanakan pembelajaran yang mendidik; (4) menguasai prinsip 
dan prosedur asesment proses dan hasil belajar peserta didik; (5) merencanakan dan melaksanakan asesment proses dan hasil belajar peserta didik; (6) memanfaatkan hasil asesment untuk perbaikan pembelajaran; (7) merencanakan kajian ilmiah dalam rangka meningkatkan pembelajaran; (8) menguasai manajemen kelas.

c. Kompetensi Kepribadian

beberapa kompetensi pribadi yang semestinya ada pada seorang guru disamping memiliki pengetahuan yang dalam ia juga harus memiliki pengetahuan tentang perkembangan peserta didik serta kemampuan untuk memberlakukan mereka secara individual (Hamzah B. Uno, 2007).

d. Kompetensi sosial

Manusia memiliki kodrat sebagai makluk sosial dan maklul etis maka dalam hal ini guru harus dapat memperlakukan peserta didiknya secara wajar dan bertujuan agar tercapai optimalisasi potensi bagi diri masing-masing peserta didik.

UNY mempunyai tugas menyelenggarakan program pendidikan akademik dan atau pendidikan professional sejumlah disiplin ilmu pengetahuan, teknologi, dan atau kesenian. Mengembangkan ilmu kependidikan dan non kependidikan serta mendidik tenaga akademik dan professional di bidang kependidikan dan non kependidikan (Kurikulum FISE UNY, 2009: 1). Mahasiswa kependidikan, sebagai calon guru harus memiliki kompetensi pedagogik, kepribadian, sosial, dan professional. Salah satu tolok ukur mahasiswa yang memiliki kompetensi professional calon guru adalah harus lulus mata kuliah PPL.

Berdasarkan UU no 14 tahun 2005 tentang Guru dan Dosen, guru adalah pendidik professional dengan tugas utama mendidik, mengajar, membimbing, mengarahkan, melatih, menilai, dan mengevaluasi peserta didik pada pendidikan anak usia dini jalur pendidikan formal, pendidikan dasar, dan pendidikan menengah. Oleh karena itu calon guru professional adalah guru yang menguasai perencanaan dan pelaksanaan pembelajaran. Perencanaan dan pelaksanaan pembelajaran menjadi salah satu instrument portofolio sertifikasi guru dalam jabatan (Dirjen Mutu Pendidikan dan Tenaga Kependidikan Buku 3, 2010: 24-25).

Penilaian meliputi prapembelajaran, yaitu mempersiapkan siswa untuk belajar, melakukan kegiatan apersepsi. Penilaian kegiatan inti pembelajaran, yaitu penguasaan materi, pengkaitan materi dengan pengetahuan lain yang relevan, kejelasan penyampaian materi, pengkaitan materi dengan realitas kehidupan. Penilaian strategi pembelajaran, yaitu pelaksanaan pembelajaran sesuai kompetensi, keruntutan, peguasaan kelas, kontekstual, dan pengelolaan waktu yang sesuai. Penuilaian media pembelajaran, yaitu efektivitas penggunaan media, pelibatan siswa dalam pemanfaatan media, dan kemenarikan pesan media. Penilaian keterlibatan siswa, yaitu partisipasi aktif siswa, respon terhadap siswa, dan antusisme terhadap siswa dalam pembelajaran. Penulaian proses dan hasil belajar, yaitu pemantauan hasil pbelajar, dan penenilaian akhir sesuai kompetensi. Penilaian kebahasaan, 
yaitu penggunaan bahasa lisan, tulis, sesuai kaidah bahasa yang baik, dan benar. Penuilaian penutup, yaitu refleksi, perangkuman, maupun arahan (Dirjen Mutu Pendidikan dan Tenaga Kependidikan Buku 3, 2010: 40-41).

PPL I atau yang biasa dikenal dengan istilah micro teaching merupakan langkah awal latihan calon guru dalam melaksanakan kegiatan pembelajaran, mikro teaching menjadi ajang pelatihan yang cukup komprehensif dari seorang calon guru dari kegiatan merencanakan pembelajaran, melaksanakan pembelajaran sesuai dengan skenario dan mengevaluasi proses dan hasil pembelajaran. Kelemahan dari micro teaching adalah situasi yang ada adalah bukan situasi sebenarnya karena yang dihadapi adalah teman-teman sendiri. Micro teaching ini juga dikenal dengan istilah peer teaching.

Microteaching dilaksanakan di program kependidikan S1 sebelum mahasiswa diterjunkan ke sekolah-sekolah untuk melaksanakan realteaching atau dikenal dengan istilah PPL. FISE UNY disamping melaksanakan microteaching, juga telah melaksanakan realmicroteaching bekerjasama dengan beberapa sekolah mitra setiap hari Sabtu pada setiap semester genap. Pelaksanaan realmicroteaching diharapkan dapat meningkatkan keprofesionalan mahasiswa calon guru.

Untuk mengetahui pengaruh keterlaksanaan realmicroteaching, akan diteliti seberapa besar pengaruh program itu terhadap keterampilan mahasiswa dalam mengajar. Pendapat guru, dosen, dan mahasiswa diperlukan untuk diminta pendapatnya dalam bentuk angket. Hasil angket per butir akan dianalisa dan disimpulkan dalam bentuk laporan penelitian.

Penelitian ini mengacu pada pandangan atau pendapat. Hasil penelitian ini akan digunakan untuk mengambil keputusan bahwa realmicroteaching akan dilanjutkan atau tidak. Pelaksanaan realmicroteaching yang telah berlangsung selama enam tahun membutuhkan biaya sangat besar, dan kemanfaatannya dirasakan kurang maka ada kecenderungan untuk ditinjau ulang bahkan dapat dihentikan. Namun demikian apabila hasinya lebh baik, maka perlu dilanjutkan. Untuk perlu penelitian ini hanya perlu data ya dan tidak. Artinya ya berarti sangat urgen, dan tidak berarti tidak penting.

\section{Metode Penelitian}

Desain penelitian ini yaitu deskriptif dengan jenis penelitian evaluasi. Evaluasi dilakukan terkait implementasi program realmicroteaching di FISE UNY dengan cara survey.

Populasi penelitian ini yaitu pihak-pihak yang terkait program realmicroteaching sebagai berikut: guru sekolah mitra, dosen PPL I, Tenaga kependidikan FISE, dan Siswa sekolah mitra. Sampel penelitian diambil secara acak sebanyak setidaknya 30\% dari populasi yang ada. Adapun sampel yang diperoleh: Guru mitra 27 orang, tenaga administratif 7 orang, siswa 49 dan dosen 16 orang. 
Teknik pengumpulan data yang digunakan dalam penelitian ini berupa angket. Instrumen yang digunakan dalam penelitian ini berupa kuesioner yang berisi dua alternatif jawaban yaitu "ya" atau "tidak" sesuai kondisi senyatanya di lapangan.

Semua data yang dikumpulkan melalui instrumen dianalisis dengan menggunakan teknik analisis persentase kemudian dideskripsikan dan diambil kesimpulan tentang masing-masing komponen atas dasar kriteria yang telah ditentukan.

\section{Hasil Penelitian}

Hasil penelitian mendeskripsikan frekuensi jawaban dari responden tentang implementasi program realmicroteaching di Fakultas Ilmu Sosial dan Ekonomi. Deskripsi jawaban dibedakan menjadi lima bagian sebagai jawaban rumusan masalah penelitian. Data yang diperoleh adalah data primer dan data sekunder. Data primer berupa data pendapat para responden. Responden terdiri dari para guru dari sekolah-sekolah mitra, yaitu SMK N 1 Depok, SMK N 1 Yogyakarta, SMA N 6 Yogyakarta, SMA N 4 Yogyakarta, SMA N 11 Yogyakarta, SMP N 1 Yogyakarta, SMP N 1 Depok, dan SMP Muhammadiyah 1 Depok. Responden lainnya adalah para dosen dari Prodi Pendidikan Ekonomi, Prodi Pendidikan Akuntansi, Prodi Pendidikan Administrasi, Prodi Pendidikan Sejarah, Prodi Pendidikan Sosiologi, Prodi PKn, Prodi Pendidikan Geografi dan Prodi IPS di FISE UNY. berikut.

Berdasarkan hasil angket yang diedarkan maka diperoleh hasil seperti

1. Keterampilan mahasiswa pada saat PPL

Data mengenai keterampilan mahasiswa pada saat PPL diperoleh dari jawaban responden terhadap kuesioner yang diperoleh dari dosen ketika membimbing mahasiswa PPL yang pernah mengikuti realmicroteaching. Pertanyaan yang dibuat mengenai keterampilan mahasiswa antara lain; realmicroteaching membuat mahasiswa lebih percaya diri, dewasa, tahu etika, menguasai materi, menguasai penggunaan media pembelajaran.

Berkaitan dengan ketrampilan mahasiswa, berikut ini table hasil survey.

Tabel Pendapat guru tentang ketrampilan mahsiswa

\begin{tabular}{|l|l|l|l|}
\hline No. & Pendapat & Jumlah & Persen (\%) \\
\hline 1 & Ketrampilan meningkat & 17 & 63,0 \\
\hline 2 & Ketrampilan tidak meningkat & 4 & 14,8 \\
\hline 3 & Tidak memberikan pendapat & 6 & 22,2 \\
\hline & & 27 & 100 \\
\hline
\end{tabular}

Gambaran umum rata-rata jawaban dari responden tentang peningkatan keterampilan mahasiswa pada saat PPL yaitu sekitar (63\%) menyatakan mahasiswa PPL mengalami peningkatan keterampilan. 
Sebanyak 22,2\% tidak memberikan pilihan jawaban dan sisanya 14,8\% menyatakan tidak mengalami peningkatan.

Terhadap pertanyaan tersebut, maka setelah dilakukan penelitian mendalam dengan wawancara dapat diuraikan bahwa rata-rata mahasiswa memiliki ketrampilan penguasaan media pembelajaran, tetapi bukan berasal dari hanya melaksanakan realmicroteaching saja, namun jauh sebelum itu telah banyak mempelajari dalam perkuliahan yang berkaitan dengaan teknologi pembelajaraan. Jawaban diperoleh dari pernyataaan dosen yang juga sebagai dosen pembimbing microteaching. Menurut para dosen, peningkatan ketrampilan terjadi dalam satu semester dengan lebih dari enam pertemuan, dengan proses yang semula kurang baik menjadi layak. Demikian pula berkaitan dengan rasa percaya diri, diawali dengan tampil pada awal latihan microteaching, yang kurang bagus, dan terus berlatih hingga mencapai layak tampil di depan kelas. Berkaitan dengan kedewasaan dan etika juga melewati proses panjang, tidak dalam sekejap aatau satu semester saja, tetapi perlu waktu bertahun-tahun, bahkan berproses sejak pendidikan usia dini. Demikian juga untuk penguasaan materi juga diperoleh dalam jangka panjang, bukan karena proses pada realmicroteaching yang hanya dilakukan hanya sekali tersebut. Pendek kata, realmicroteaching memang memberi tambahan ketrampilan kepada mahasiswa namun relatif sangat sedikit karena hanya dilaksanakan hanya sekali. Peerteachinglah yang banyak memberi kontribusi ketrampilan para mahasiswa menjelang melaksanakan PPL.

2. Biaya penyelenggaraan realmicroteaching dari fakultas

Informasi mengenai besaran biaya penyelenggaraan diperoleh dari bagian keuangan FISE UNY. Data menunjukkan bahwa setiap penyelenggaraan realmicroteaching menelan biaya sekitar Rp60.000.000,- dan dilaksanakan dalam satu tahun sekali.

3. Bagaimana pendapat guru terkait optimalisasi pekerjaan dengan diselenggarakannya realmicroteaching?

Data mengenai optimalisasi pekerjaan guru yang diperoleh dari pertanyaan responden seperti table berikut.

Tabel Kesediaan guru dalam pelaksanaan microteaching

\begin{tabular}{|l|l|l|l|}
\hline No. & Sikap & Jumlah & Persen $(\%)$ \\
\hline 1 & Senang melaksanakan MT & 15 & 68,1 \\
\hline 2 & Tidak senang melaksanakan MT & 7 & 31,9 \\
\hline & & 22 & 100 \\
\hline
\end{tabular}

Hasil yang diperoleh menunjukkan bahwa sebagian besar atau 22 responden $(81,4 \%)$ guru siap membantu pelaksanaan realmicroteaching, dan hanya 5 responden $(18,6 \%)$ tidak memberi jawaban. Dari $81 \%$ responden, sebagian besar atau 15 responden $(68,1 \%)$ merasa senang melaksanakan realmicroteaching, dan hanya 7 responden $(31,9 \%)$ tidak senang dengan keberaadaaaan microteaching. Disamping itu besaran insentif yang diterima cukup menggiurkan. Informasi lebih jauh dikemukakan bahwa 
pelaksanaan realmicroteaching mengganggu anak belajar secara regular walau hanya sekali.

4. Bagaimana sikap siswa?

Tabel Sikap siswa dalam pelaksanaan microteaching

\begin{tabular}{|l|l|l|l|}
\hline No. & Sikap & Jumlah & Persen (\%) \\
\hline 1 & Senang melaksanakan MT & 41 & 83,7 \\
\hline 2 & Tidak senang melaksanakan MT & 8 & 16,3 \\
\hline & & 49 & 100 \\
\hline
\end{tabular}

Sikap siswa dengan pelaksaanaan realmicroteaching sebagian besar, yaitu 41 siswa $(83,7 \%)$ menyatakan senang dengan pelaksanaan realmicroteaching, dan sisanya 8 siswa $(16,3 \%)$ tidak senang mengikuti program microteaching.

5. Bagaimana sikap dosen?

Berikut table pendapat dosen

Tabel Sikap Dosen dalam pelaksanaan microteaching

\begin{tabular}{|l|l|l|l|}
\hline No. & Sikap & Jumlah & Persen (\%) \\
\hline 1 & Senang melaksanakan MT & 4 & 25 \\
\hline 2 & Tidak senang melaksanakan MT & 9 & 56,2 \\
\hline 3 & Tidak bersikap & 3 & 18,8 \\
\hline & & 16 & 100 \\
\hline
\end{tabular}

Sebagian besar dosen, yaitu 9 responden (56,2\%) tidak senang melaksanakan reaalmicroteaching, hanya 4 responden atau $25 \%$ senang melaksanakan realmicroteaching, dan hanya $18,8 \%$ bersikap netral.

6. Bagaimana sikap tenaga administratif?

Hal berbeda disampaikan oleh para staf administrasi, sebanyak tujuh staff administrasi mereka keberatan karena mengganggu hari libur serta honor terlalu kecil.

\section{Penutup}

Berdasarkan hasil analisis data, maka gambaran implementasi program realmicroteaching di FISE UNY sebagai berikut:

Keterampilan mahasiswa pada saat PPL sekitar (63\%) menyatakan mahasiswa PPL mengalami peningkatan keterampilan. Sebanyak 22,2\% tidak memberikan pilihan jawaban dan sisanya $14,8 \%$ menyatakan tidak mengalami peningkatan. Biaya penyelenggaraan realmicroteaching dari fakultas sebesar Rp. 60.000.000,sehingga membebani anggaran pengembangan tri dharma perguruan tinggi. Guru menyatakan bahwa sebagian besar $(81,4 \%)$ siap membantu pelaksanaan realmicroteaching dan sebagian besar $(68,1 \%)$ merasa senang melaksanakan realmicroteaching. Sekitar $(31,9 \%)$ saja yang menyatakan bahwa tidak senang melaksanakan realmicroteaching. Informasi lebih jauh dikemukakan bahwa pelaksanaan realmicroteaching mengganggu hari libur dan acara keluarga. 
Disamping itu besaran insentif yang diterima lebih rendah berbanding pekerjaan yang dilakukan. Sikap dosen dengan pelaksaanaan realmicroteaching sebagian besar (56,2\%) menyatakan tidak senang (keberatan) dengan pelaksanaan realmicroteaching. Sikap siswa dengan pelaksaanaan realmicroteaching sebagian besar $(83,7 \%)$ menyatakan senang dengan pelaksanaan realmicroteaching

\section{Daftar Pustaka}

Direktorat Jenderal Mutu Pendidikan dan Tenaga Kependidikan, 2010. Sertifikasi Guru dalam jabatan, Buku 3. Jakarta: Kemdiknas.

Hamzah B. Uno. 2010. Perencanaan Pembelajaran. Jakarta: Bumi Aksara.

Kurikulum FISE UNY 2009.

Peraturan Pemerintah Nomor 19 Tahun 2005 Tentang Standar Nasional Pendidikan.

Tim. 2009. Panduan KKN-PPL UNY. Yogyakarta: UPPL UNY

Undang-Undang Nomor 14 Tahun 2006 Tentang Guru dan Dosen

Biodata Suhadi Purwantara, Lektor Kepala 550, aktif menulis di Jurnal Informasi, Geo media, Jurnal Penelitian IPTEK dan Humaniora dengan beberapa artikel antara lain Mengenal Beberapa Macam Bencana Alam dan Akibatnya, Peran Ilmu Geografi dalam Pengajaran Ilmu Sosial, Perkembangan Pemikiran Geografi Dalam Kontribusinya Pada Ilmu Wilayah, Manfaat Remotesensing dalam Oseanografi, Aplikasi Ilmu Geografi Dalam Perencanaan Pembangunan, Air Tanah Pantai Parangtritis Rawan Intrusi, Potensi Mataair Cerme untuk Kebutuhan Irigasi, Australia Negara Maju di Pojok Dunia, Perbedaan Pulau Honsu dan Pulau Jawa, dan lain-lain. 